\title{
The Magnetic Hysteresis of Rocks and Minerals at High Temperatures
}

\author{
By E. R. DEUTSCH \\ Physics Department, Imperial College of Science and Technology, London, England.
}

(Received Oct. 1, 1956)

\begin{abstract}
The coercivity, remanence and saturation magnetization of a number of minerals and rocks have been obtained as a function of temperature, using alternating fields up to 2300 oersteds. These results suggest that most of the specimens examined can retain thermoremanence for long periods, even at high temperatures. Irregularities occurring in some of the temperature curves indicated the presence of more than one ferromagnetic constituent. Heat treatment in several cases caused considerable changes in the hysteresis curves measured at atmospheric temperatures. The thermomagnetic behaviour of two basalts has supported the view that the reversed magnetization of certain rock formations is due, not to abnormal magnetic properties on the part of the material concerned, but to a past reversal of the geomagnetic field.
\end{abstract}

\section{Introduction}

As a result of field and laboratory work undertaken since 1946 by the Geophysics Department of the Imperial College, it has been discovered that the Tertiary tholeite dyke system of Northern England is permanently magnetized in a direction opposite that of the present earth's field [1]. It was subsequently shown [2], [3] that many of the Tertiary lava flows and dykes of the Isle of Mull possess statistically significant mean directions of magnetization, some of which are in opposition to the geomagnetic field, whilst others nearly coincide with it. Reversals in the polarization of igneous rock formations have been discovered in many countries, including South Africa, Iceland, Japan, France, etc.

Igneous rocks usually acquired their natural residual magnetism while cooling in the earth's magnetic field from temperatures above their Curie points. This "thermoremanence" may exceed by a large factor the magnetization induced in the rock by the present geomagnetic field at atmospheric temperatures. Laboratory experiments carried out on the Mull rocks showed that nearly all the significantly polarized specimens exhibited thermoremanence. When cooled from above their Curie points, they always became magnetized in the direction of the acting field. To explain the occurrence of reversed magnetism in the rock formations concerned, it was postulated that the geomagnetic field itself was reversed at the time when they originally cooled through the Curie points of their ferromagnetic constituents. 
As an alternative to this hypothesis, Néel [4] and others have suggested that an intrinsic property of the rocks themselves may account for their reversed polarization. In support of this, a number of Japanese specimens do acquire thermoremanence in the laboratory, in opposition to a small applied field [5], [6]. An ultimate decision in favour of one or the other of the two basic theories thus requires further research into the magnetic and thermomagnetic properties of rocks.

In a paper by Bruckshaw and Rao, [7] experiments are described in which the magnetic hysteresis of rock specimens, mainly from the tholeiite dykes, was measured in fields of $750 \mathrm{Oe}$. Large coercivities were obtained, comparable to those of certain magnet steels. These data permitted the assumption, essential to the field reversal hypothesis, that the inversely magnetized Tertiary rocks have retained a large proportion of their original polarization for 30 million years, perhaps mainly in opposition to the earth's field.

The present paper deals with the results of an extension of the above work into a study of the magnetic hysteresis of minerals and rocks at temperatures up to their Curie points. The experimental method used is the subject of a separate paper in this issue of the Journal. The knowledge thus gained can allow deductions to be made about the stability of thermoremanence. For example, the coercivity of a basalt with its Curie point at $580^{\circ} \mathrm{C}$ may exceed -100 oersteds in the entire range from $500^{\circ} \mathrm{C}$ to atmospheric temperature. It is then safe to conclude that the rock will be capable of retaining the direction of its original thermoremanence not only for long periods and in opposition to the ambient field, but even if partial reheating should subsequently occur. Very few data on this subject have been published. Koenigsberger [8] measured the coercivity of a hematite specimen up to $500^{\circ} \mathrm{C}$ and found that it decreased rapidly at first, but more gradually at the higher temperatures. Akimoto [9] reported a similar behaviour for the case of the ferromagnetic constituents separated from an andesite sample, while Forrer [10] observed that the coercivity of a magnetite crystal decreased steadily up to its Curie point.

\section{Results}

If the specimens were saturated at room temperature in a field of $2300 \mathrm{Oe}$, the usual terms coercivity $\left(H_{c}\right)$, remanence $\left(I_{r}\right)$ and saturation magnetization $\left(I_{s}\right)$ will be used. If saturation was not achieved at $20^{\circ} \mathrm{C}$, the corresponding terms coercive force $\left(H_{c}{ }^{\prime}\right)$, residual magnetization $\left(I_{r}{ }^{\prime}\right)$ and maximum magnetization $\left(I_{s}{ }^{\prime}\right)$ will be used at all temperatures.

The rock and mineral samples were cut into rectangular prisms of approximate $1.2 \mathrm{~cm}^{2}$ section by $3.0 \mathrm{~cm}$ length, the field being applied perpendicular to the long axis. Magnetite, pyrrhotite, franklinite and one rock type, basalt, were investigated. Except for one powdered magnetite, all specimens were cut from natural rock samples.

(1) Magnetite

(a) Magnetite from Pretoria, South Africa, (specimen $M 1$ ) was observed at $20^{\circ} \mathrm{C}$ and then at a sequence of temperatures as the rock cooled from $604^{\circ} \mathrm{C}$. The maximum 
field $H_{0}$ was $2300 O e$. in all cases.

The results (Fig. 1) show the Curie point of the specimen in the range $580-585^{\circ} \mathrm{C}$, in good agreement with the value for pure magnetite. The saturation magnetization shows its sharpest drop between 400 and $435^{\circ} \mathrm{C}$. On the basis of the domain theory, $I_{s}$ represents the sum of the spontaneous magnetizations of all the domains in a material and, for pure magnetite, the curve of $I_{s}$ against $T$ should be smooth, $I_{s}$ falling more and more rapidly as the Curie point is approached. Specimen $M 1$ therefore is likely to contain a second constituent with its Curie point in the neighbourhood of $435^{\circ} \mathrm{C}$, possibly a titanomagnetite, which is the name generally given to a magnetite containing $\mathrm{TiFe}_{2} \mathrm{O}_{4}$ (ulvöspinel) in solid solution. Since ulvöspinel is paramagnetic, its concentration in the solid solution determines the magnetic properties, including the Curie point, of the titanomagnetite.

The temperature curves were all irreversible (Fig. 1), the value of $I_{s}$ at the end of the experiment being only 17\% of that determined before the specimen had been heated. Akimoto [11], [12] also obtained irreversible $I_{s}-T$ curves. These results suggest that specimen $M 1$ initially contained maghemite ( $r$-ferric oxide) which turned into the $\boldsymbol{a}$-form (hematite) after heating. Due to defects in its crystal lattice, maghemite can be strongly ferrimagnetic, but it becomes unstable when heated and turns into hematite at $275^{\circ} \mathrm{C}$, according to some observers, and at $400-800^{\circ} \mathrm{C}$, according to others. The Curie point of both ferric oxides is given as $675^{\circ} \mathrm{C}$. Hematite is possibly ferromagnetic, with low values of $I_{s}$ and $I_{r}$ but high values of $H_{e}$, possibly several thousand oersteds [13]. This would account for the uncommonly large coercivity $(-613 \mathrm{Oe}$.) exhibited by the specimen at $20^{\circ} \mathrm{C}$ after heating. Koenigsberger [14] also examined magnetite from Pretoria and found $H_{c}=-380 \mathrm{Oe}$. for a solid sample and $H_{c}=-450$ to -570 Oe for a powder. On the other hand, he observed that "titanomaghemites" yielded principally magnetite rather than hematite after prolonged heating to $700^{\circ} \mathrm{C}$. The fact that no Curie point above $585^{\circ} \mathrm{C}$ was observed in specimen $M 1$ suggests magnetite as the end product, but since $\boldsymbol{o}$-ferric oxide is only very weakly magnetic, especially at high temperatures, its presence may have remained undetected. A final decision must await chemical or X-ray analysis of the material.

(b) Specimen $M 2$ was cut from the same original sample of Pretoria magnetite as $M 1$, and $H_{r}$, $I_{r}$ and $I_{s}$ were measured at room temperature before heat treatment,

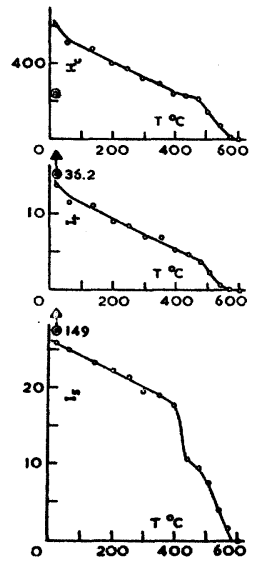

Fig. 1 Specimen M1. Magnetite

Points obtained $H_{c}$ and $H_{c}^{\prime}$ in oersteds ; $I_{r}, I_{r^{\prime}}, I_{s}$ and $I_{s}^{\prime}$ in arbitrary units.

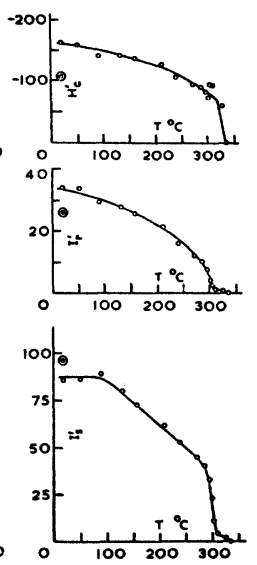

Fig. 2 Specimen Fig. 3 Specimen
M3. Magnetite $P 1$. Pyrrhotite

Fig. 2 Specimen Fig. 3 Specimen
$M 3$. Magnetite $P 1$. Pyrrhotite before heating; 0 whilst heating;

$O$ whilst cooling. 
and after heating to $600^{\circ} \mathrm{C}$ on four successive occasions. By far the greatest changes resulted from the first heat treatment (Table I), and these were of the same order of

Table I. Specimen M2-changes due to heat treatment

$T=20^{\circ} \mathrm{C} . \quad N=$ Number of times the specimen has been heated to $600^{\circ} \mathrm{C}$.

\begin{tabular}{|c|c|c|r|}
\hline & oersteds & \multicolumn{2}{|c|}{ arbitrary units } \\
\hline$N$ & $H_{c}$ & $I_{r}$ & \multicolumn{1}{|c|}{$I_{s}$} \\
\hline 0 & -273 & 46.0 & 153.1 \\
1 & -591 & 16.3 & 31.1 \\
2 & -672 & 8.2 & 10.6 \\
3 & -682 & 7.9 & 9.3 \\
4 & -607 & 8.0 & 14.0 \\
\hline
\end{tabular}

magnitude as in specimen $M 1$.

(c) As several observers have pointed out, [15] the magnetic properties of rocks can be reduced essentially to those of the ferromagnetic minerals contained in them. Magnetite from Tintagel (Cornwall) was powdered and the magnetic constituent extracted with a magnet. Sufficient of the ungraded powder was added to plaster of Paris to produce an artificial specimen containing about 25\% by weight of magnetite. Measurements were made at temperatures rising from 20 to $600^{\circ} \mathrm{C}$, with $H_{0}=2300 \mathrm{Oe}$.

The Curie point was again in the neighbourhood of $585^{\circ} \mathrm{C}$ (Fig. 2), but the $I_{s}^{\prime}-T$ curve here resembles the $I_{s}-T$ curves of a pure ferromagnetic material. The $H_{c}^{\prime}-T$ and $I_{r}^{\prime}-T$ curves exhibit a peculiar feature, both showing a rapid rise up to about $100^{\circ} \mathrm{C}$. This effect may well be due to incomplete saturation at normal temperature. The location and magnitude of the resulting maximum would then depend on the manner in which $I_{s}^{\prime}, I_{r}^{\prime}$ and $H_{c}^{\prime}$ vary with field and temperature, respectively.

(2) Pyrrhotite

(a) Specimen $P 1$, of undetermined origin, was examined upon cooling from $345^{\circ} \mathrm{C}$ in a field $H_{0}=1200 \mathrm{Oe}$. With increasing $T$ (Fig. 3), the decrease of $H_{c}^{\prime}$ is more gradual than that of either $I_{r}^{\prime}$ or $I_{s}^{\prime}$, but all three curves fall to zero at $333^{\circ} \mathrm{C}$. The sharpest drop in $I_{r}^{\prime}$ and $I_{s}^{\prime}$ occurs near $300^{\circ} \mathrm{C}$, so that the region between 300 and $333^{\circ} \mathrm{C}$ possibly includes two Curie points. The $I-H$ loops in Fig. $4(\mathrm{a}-\mathrm{d})$ show the rapid increase of hysteresis for a small temperature drop just below $333^{\circ} \mathrm{C}$.
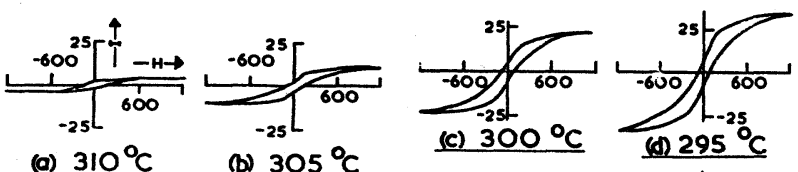

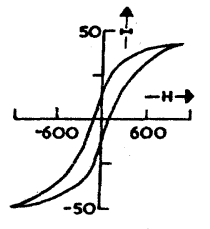

(e) $270 \% \mathrm{C}$

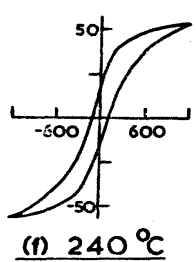

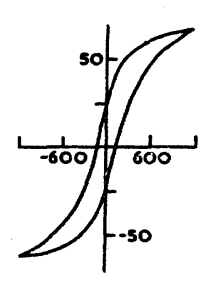

(9) $210^{\circ} \mathrm{C}$

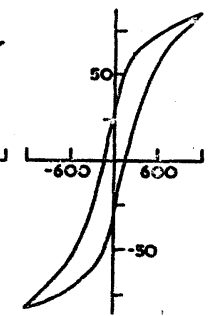

(n) 130 or

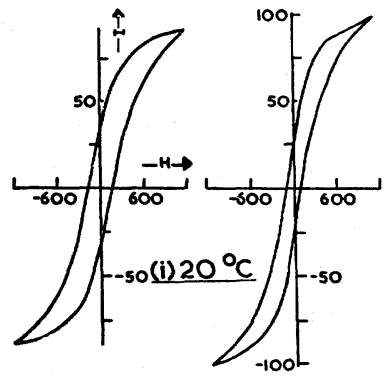

After heating Before heating

Fig. 4 Specimen $P 1$. Pyrrhotite. $I-H$ Curves.

At $20^{\circ} \mathrm{C}$ the hysteresis loop showed an approach to saturation. Several studies [16] have revealed the strong anisotropy of pyrrhotite crystals, which in certain cases 
attain saturation only in very high fields. Davis [17] investigated powdered pyrrhotite which was not saturated at $3340 \mathrm{Oe}$. On the other hand, the hysteresis loop of a pyrrhotite specimen obtained by Tzu-Chang-Wang [18] shows near-saturation at $501 O e$., $H_{c}$ being of the same order as in specimen $P 1$.

(b) Specimen $P 2$, from Sudbury (Ontario), retained ferromagnetic properties beyond the Curie point of pure pyrrhotite and was examined as it cooled from $590^{\circ} \mathrm{C}$ in a field $H_{0}=2300 \mathrm{Oe}$. (Fig. 5). The $I_{s}^{\prime}-T$ curve terminates at $560-580^{\circ} \mathrm{C}$, which is near the Curie point of magnetite. Its shape suggests that this curve contains two "simple" components of magnetite and pyrrhotite, respectively. Below the Curie point of pyrrhotite the curve is thus a resultant of the $I_{s}^{\prime}-T$ or $I_{s}-T$ curves of each of these constituents, whilst above that temperature it represents magnetite alone. From the intersection of tangents drawn to the $I_{s}^{\prime}-T$ curve, the Curie point of the pyrrhotite was estimated to be $320-325^{\circ} \mathrm{C}$. The irregular trend of $H_{c}^{\prime}$ near $300^{\circ} \mathrm{C}$ may have arisen as follows:-

At room temperature, the measured value of $H_{c}^{\prime}$ is intermediate between the separate coercive forces of pyrrhotite and magnetite. A comparison of Figs. 2 and 3 suggests that, in the neighbourhood of $300^{\circ} \mathrm{C}, H_{r}^{\prime}$ of the magnetite is larger than that of the pyrrhotite, but that they both decrease with rising temperature. However, the contribution of the pyrrhotite to the total magnetization also diminishes until, at its Curie point, the value of the resultant coercive force is a maximum and represents magnetite alone. It follows that a minimum exists below this temperature, as confirmed in Fig. 5. A similar mechanism may account for the observed irregularity in the $I_{r}^{\prime}-\mathrm{T}$ curve.

(3) Franklinite

All franklinite specimens have come from the Franklin (New Jersey) area, and $F 1$ to $F 4$ have been cut from a single sample.

(a) Specimen $F 1$ was investigated as it cooled from $605^{\circ} \mathrm{C}$ in a field $H_{0}=1200 \mathrm{Oe}$. The graphs in Fig. 6 suggest a Curie point just above $600^{\circ} \mathrm{C}$. The $H_{c}^{\prime}$ maximum may be due to a mechanism similar to that responsible for the $H_{c}{ }^{\prime}$ maximum of $M 3$; this now occurred at $560^{\circ} \mathrm{C}$, probably because saturation was not attained below that temperature. Towards room temperature, the trends of the $I_{s}^{\prime}-T$ and $I_{r}^{\prime}-T$ curves become concave upwards, instead of downwards as expected, the greatest changes occurring in the narrow range

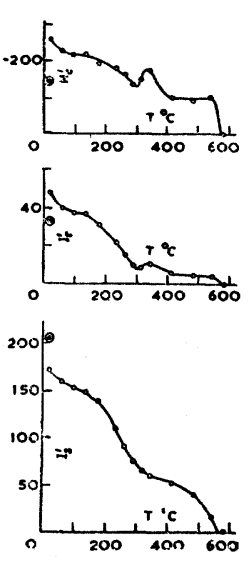

Fig. 5 Specimen I'2. Pyrrhotite
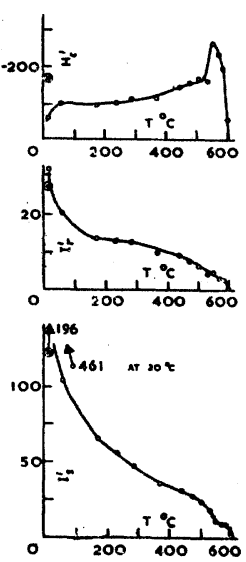

Fig. 6 Specimen F1. Franklinite
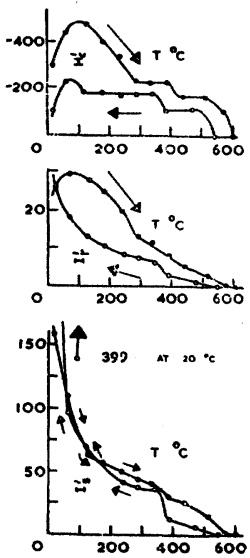

Fig. 7 Specimen

F2. Franklinite

Points obtained $\odot$ before heating; $\rightarrow \odot$ whilst heating; $\leftarrow \bigcirc$ whilst cooling. $H_{c}^{\prime}$ in oersteds; $I_{r}{ }^{\prime}$ and $I_{s}^{\prime}$ in arbitrary units. 
between 61 and $20^{\circ} \mathrm{C}$, where $I_{s}^{\prime}$ increased by a factor of 4.4 and $H_{c}^{\prime}$ dropped sharply. Since ten hours had elapsed between the measurements at 61 and $20^{\circ} \mathrm{C}$, respectively, it was considered possible that these marked changes in magnetic properties might depend on time.

(b) Specimen $F 2$ was investigated during the heating as well as the cooling process. The field was increased to $2300 \mathrm{Oe}$, sufficient to cause saturation not far above room temperature; hence the location of both coercive force maxima at relatively low temperatures, (Fig. 7). Upon cooling from $610^{\circ} \mathrm{C}$, the Curie point was lowered by about $60^{\circ} \mathrm{C}$. Ten hours again elapsed before the final measurement was made, and the changes occurring between 62 and $20^{\circ} \mathrm{C}$ were of the same order of magnitude as those observed for $F 1$ in the corresponding temperature range.

(c) To determine the time interval during whicil the large increases in magnetization occurred the experiment was repeated with a third specimen, F3. Again this was heated above $600^{\circ} \mathrm{C}$. After cooling to $50^{\circ} \mathrm{C}$, it was taken out of the furnace and transferred to an apparatus where volume susceptibility $k$ was measured in a small field, at repeated intervals.

Table II. Specimen F3-Volume susceptibility

$t=$ time in minutes since first reading was taken.

$k=$ incremental volume susceptibility in c.g.s. units $\times 10^{-6}$.

\begin{tabular}{|c|c|c|c|c|c|}
\hline $\mathrm{t}$ & $\mathrm{k}$ & $\mathrm{t}$ & $\mathrm{k}$ & $\mathrm{t}$ & $\mathrm{k}$ \\
\hline $\mathbf{C}^{*}$ & 4,700 & 7.5 & 19,170 & 15.0 & 21,270 \\
\hline 0 & 9,630 & 8.5 & 19,680 & 16.0 & 21,460 \\
\hline 4.0 & 15,210 & 10.5 & 20,850 & 17.0 & 21,590 \\
\hline 6.0 & 17,600 & 13.5 & 21,170 & 19.0 & 21,600 \\
\hline
\end{tabular}

* Reading taken before the specimen was heated.

Table II shows that $k$ increased steadily for the first 10 minutes and then approached a stable value. The reading at $t=19$ minutes should correspond to a temperature of $20^{\circ} \mathrm{C}$ and at $t=0$ the temperature should be in the range $30-40^{\circ} \mathrm{C}$. In the time elapsed $k$ had increased by a factor of 2.2 , which is of the same order as the increases in $I_{s}^{\prime}$ for $F 1$ and $F 2$, in roughly the same temperature interval. The conclusion appears warranted that temperature rather than time effects were responsible for the peculiar magnetization changes observed in specimens $F 1-F 3$. It may be suggested that the first heating caused chemical alterations in the material, resulting in the formation of a new constituent having its Curie point near room temperature, or slightly above.

(d) To investigate the possibility of chemical action, a further specimen, $F 4$, was subjected to the same heat treatment as $F 1-F 3$ and then cooled to $-50^{\circ} \mathrm{C}$ by means of solid carbon dioxide. Inspection of Fig. 8, which shows the curves obtained in a field of $1200 \mathrm{Oe}$., combined with those previously obtained for $F 1$, but adjusted to the new scale, reveals an intensely magnetic constituent with a definite Curie point 
in the low temperature range. Independent estimates from the $I_{r}^{\prime}-T$ and $I_{s}^{\prime}-T$ curves gave $15^{\circ} \mathrm{C}$ and $22^{\circ} \mathrm{C}$, respectively. This compares with the value of $61^{\circ} \mathrm{C}$, quoted by Wologdine, [19] the only reference to the Curie point of franklinite discovered in the literature. The coercive force minimum near $20^{\circ} \mathrm{C}$ is perhaps due to the interaction of the two constituents. A similar experiment with a specimen from the original franklinite sample, but which had not been heated, failed to disclose a low-temperature constituent of major intensity. The phenomena observed can thus be satisfactorily explained on the basis of chemical action caused by the heat treatment.

G.D. Nicholls, of the Department of Geology, University of Manchester, has examined some of the above specimens in powder form. $\mathrm{He}$ found that the original "franklinite" sample was really a mixture of

1. An opaque magnetic constituent, probably franklinite;

2. A green mineral, believed to be a pyroxene, or possibly willemite (zinc silicate);

3. A reddish brown mineral, perhaps tephroite (manganese silicate).

After heat treatment, mainly the opaque mineral, but also some of the silicate remained, thus confirming that chemical change had taken place. An X-ray powder photograph showed the cell dimensions of the opaque mineral to be very similar to those of magnetite, as would be expected in franklinite, but no detailed measurements were possible in this case.

It may be plausibly suggested that the chemical changes caused by heating resulted in a transfer of some $\mathrm{Zn}$ and $\mathrm{Mn}$ into the crystal lattice of the franklinite, which is a mixed ferrite, containing variable proportions of these atoms in its natural state already. It has been shown [20] that the addition to a ferromagnetic ferrite of zinc ferrite, which is paramagnetic at normal temperatures, produces mixed crystals whose Curie point is below that of the ferromagnetic ferrite. If manganese ferrite, whose Curie point is at $510^{\circ} \mathrm{C}$, is also added, the magnetic properties of the ferromagnetic ferrite, in this case franklinite, are probably further modified. A mechanism on these lines may account for the phenomena observed with specimens $F 1-F 4$.

(e) The investigation was extended to specimen $F 5$, cut from an entirely new sample of franklinite, which was measured at $H_{0}=2300 \mathrm{Oe}$. upon cooling from 548 to $20^{\circ} \mathrm{C}$, and at $0^{\circ} \mathrm{C}$. At the lower temperatures, the trend in the $I_{r}^{\prime}-T$ and $I_{s}^{\prime}-T$ curves is again concave upwards, indicating once more a second constituent, though this appears to occur now in relatively small proportions.

Upon extrapolating these curves, a Curie point of $527^{\circ} \mathrm{C}$ was obtained. Part of the sample from which specimen $F 5$ had been cut was examined by Nicholls and found to be a much purer "franklinite" than the previous specimens. This would suggest that the Curie point here observed is more representative of franklinite than that near $600^{\circ} \mathrm{C}$, as in the case of $F 1$ and $F 2$, or near $20^{\circ} \mathrm{C}$, as in the case of $F 4$. Since the composition of even a "pure" franklinite is not rigidly defined, however, it may be meaningless to assign this mineral a definite Curie point, unless such a temperature is quoted in relation to the chemical composition of the specimen 


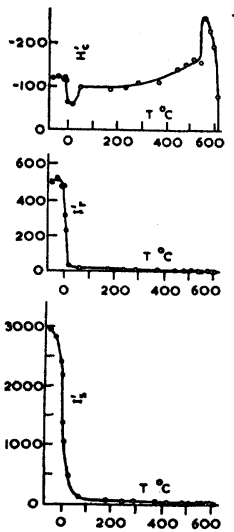

Fig. 8 Specimens $F 4$ and $F 1$. Franklinite

Franklinite
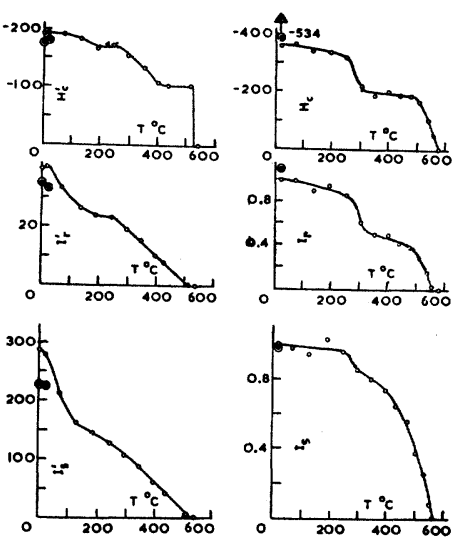

Fig. 9 Specimen Fig. 10 Specimen

F5. Franklinite

N. "Normal"

Basalt.

Points obtained $\odot$ before heating;

$O$ whilst cooling.

$H_{c}$ and $H_{c}^{\prime}$ in versteds; $I_{r}, I_{r}{ }^{\prime} I_{s}$ and $I_{s}^{\prime}$ in arbitrary units. concerned.

A more precise explanation of the phenomena here observed with franklinite would require a good deal of further work, including a detailed study of the chemical processes occurring during heat treatment.

(4) Basalt

Basalts commoniy contain magnetite or titanomagnetite as minor constituents, in which case they exhibit ferromagnetic properties. In his work on the dykes and lava flows of Mull, Vincenz [2], [3] measured the directions of magnetization of a number of oriented samples from "each rock formation he investigated, and computed a mean

direction for that formation. The significance of this mean was assessed by a statistical analysis.

The experiments described below have been conducted principally to compare the temperature curves of rocks whose natural thermoremanence had been respectively normal and inverse in direction. To be fully representative of these two types of behaviour, the specimens were chosen from rock formations whose computed mean direction of magnetization had been shown to be significant. The normally polarized rock was taken from a "normal" lava flow and the rock with inverse magnetization from a dyke whose polarization was inverse. To permit accurate measurements, the specimens were selected from a group having reasonably large susceptibilities when measured in weak fields $\left(k>4000 \times 10^{-6}\right.$ c.g.s. units). Finally, neither of the specimens used had undergone heat treatment prior to the present investigation.

Both specimens were examined at $H_{0}=2300 \mathrm{Oe}$, as they cooled from $600^{\circ} \mathrm{C}$. To facilitate comparison between them, $I_{r}$ and $I_{s}$ were plotted on a scale which made their values at $20^{\circ} \mathrm{C}$ equal to 1000 .

(a) The "normal" basalt, specimen $N$, came from a lava flow in the north eastern part of Mull. The average value of the Curie point obtained from the three curves (Fig. 10) was $572^{\circ} \mathrm{C}$, or less than $10^{\circ} \mathrm{C}$ below that of pure magnetite. The pronounced bend in the $H_{c}-T$ and $I_{r}-T$ curves above $250^{\circ} \mathrm{C}$ suggests the presence of a second constituent, with its Curie point near $300^{\circ} \mathrm{C}$.

Koenigsberger [14] examined four German late Tertiary or Quaternary basalts, containing magnetite along with titanium dioxide and excess ferrous oxide and, in one case, pyrrhotite as well. All four specimens had two Curie points each, at temperatures ranging from 450 to $620^{\circ} \mathrm{C}$, and 170 to $300^{\circ} \mathrm{C}$, respectively. $H_{c}$ of the basalts at room temperature was between -90 and -175 Oe., compared with -354 Oe obtained after 
heat treatment in the present case. However, the coercivity of the high Curie point constituent in $N$ was $-188 \mathrm{Oe}$. at $350^{\circ} \mathrm{C}$, where the $H_{c}-T$ curve is nearly horizontal; this value appears to be more in agreement Koenigsberger's results. The large coercivity $(-534 \mathrm{Oe}$.) before heat treatment may be due to a very small grain size of the ferromagnetic constituents, crystals in volcanic rocks being commonly tiny. The changes in $I_{r}$, and $I_{s}$ produced by heat treatment were small, amounting to $-10 \%$ and $+3 \%$, respectively.

(b) The "reversed" specimen, $R$, was a dolerite basalt from a dyke near Dishig, on the south shore of Loch na Keal, Mull. The main features of the three curves (Fig. 11) are simple, but it appears that a major Curie point at about $500^{\circ} \mathrm{C}$ is followed by that of a minor constituent, at about $600^{\circ} \mathrm{C}$. Since $I_{s}$ and $I_{r}$ are very small above $500^{\circ} \mathrm{C}$, the trend of $H_{c}$ is doubtful in this region, and it may vanish between 540 and $600^{\circ} \mathrm{C}$.

A major second constituent with its Curie point in a lower range of $T$ would have been required, for example, by Néel's two-component mechanisms of reversal. Apart from the small irregularities observed, however, specimen $R$ shows the behaviour of a relatively pure ferromagnetic material, whilst specimen $N$, which would be
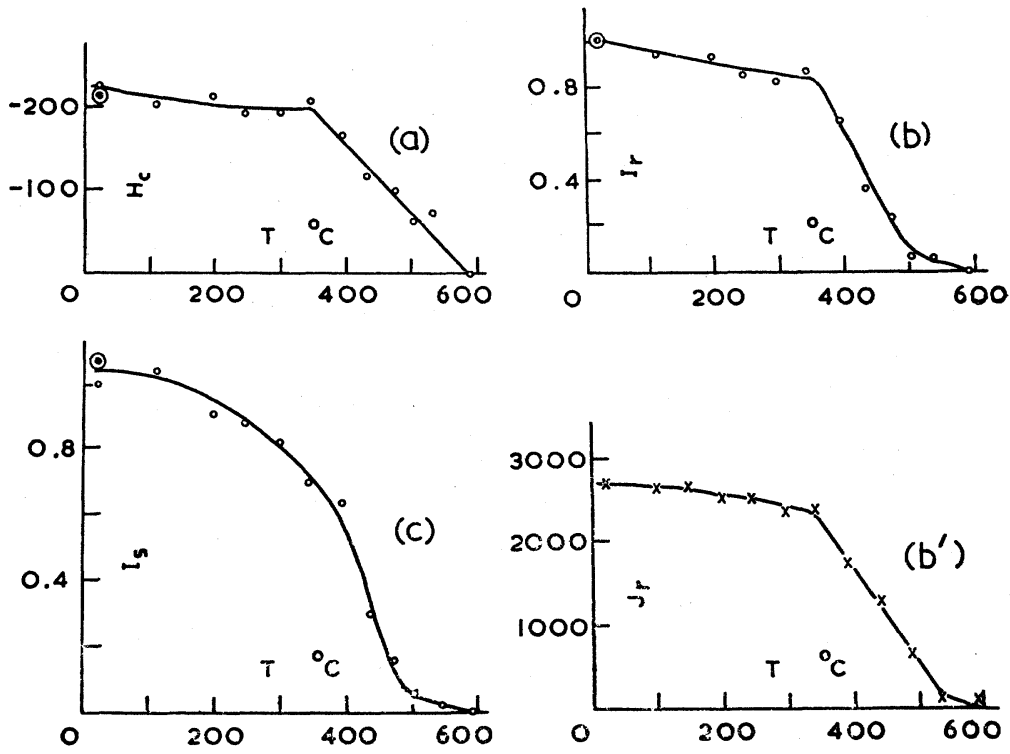

Fig. 11. Specimen $R$. "Reversed" Basalt.

Points obtained $\odot$ before heating; $\bigcirc$ whilst cooling; $\times$ after cooling. $H_{c}$ in oersteds ; $I_{r}$ and $I_{s}$ in arbitrary units ; $J_{r}$ in c.g.s. units $\times 10^{-6}$.

expected to yield "simple" curves, does reveal a strong second component. The evidence here found thus fails to justify the hypothesis that a property of the material may have caused the original reversal in the polarization of the rock.

Of all the specimens referred to in this paper, $R$ showed the least modification of its magnetic properties after heating, the changes in $I_{r}, H_{u}$ and $I_{s}$ being respectively $0,+5$ and $-7 \%$. It can thus be reasonably claimed that the heat treatment has 
caused no important chemical changes and that conclusions drawn from the laboratory data are here applicable to the conditions under which the dyke cooled through its Curie point.

J. Singh [21], until recently of the Geophysics Department, Imperial College, investigated the loss of natural remanent magnetism on heating and examined an inversely magnetized specimen from the same flow as specimen $R$. His results are shown in Fig. 11b', which bears a striking resemblance to the $I_{r}-T$ curve of specimen $R$. Again, no evidence of a second constituent in significant proportions was found.

It may be suggested that the basalt curves obtained here are, apart from the second constituent of specimen $N$, more truly representative of the properties of magnetite or titanomagnetite than those of the magnetite specimens themselves, $M 1$ and $M 2$ having changed completely after heating, whilst $M 3$ was not examined under saturation conditions.

From the geophysical point of view, the essential feature of both $H_{c}-T$ curves discussed in this section appears to be the fact that high $H_{v}$ values were attained in the range $400-500^{\circ} \mathrm{C}$. This implies that the basalts were capable of retaining thermoremanence, even at high temperatures, in opposition to an acting field. Together with the failure to find evidence in favour of the two-component mechanism, the data therefore tend to support the hypothesis that a past reversal of the earth's magnetic field has been responsible for the inverse magnetization of the rock formations concerned. However, since they were based on two specimens only, the results must be regarded as supplementary to other evidence.

\section{Summary}

Most of the minerals and rocks examined became fully or nearly saturated in an external field of $2300 \mathrm{Oe}$. The specimens behaved like normal ferromagnetic materials, their $I_{s}-T$ curves broadly resembling those of the ferromagnetic elements. $H_{c}$ was always large at normal temperatures and, in most cases, it still exceeded $-100 \mathrm{Oe}$. at $500^{\circ} \mathrm{C}$. It is safe to conclude that the rocks and minerals concerned are capable of retaining thermoremanence for long periods, even at high temperatures.

Irregular features in the temperature curves of some specimens indicated the presence of more than one ferromagnetic constituent. Probably due to chemical action in the material, the hysteresis loops measured at $20^{\circ} \mathrm{C}$ before and after the heat treatment differed considerably in some instances. In the case of a certain franklinite with its Curie point at about $600^{\circ} \mathrm{C}$ a new, strongly magnetic, constituent with its Curie point near room temperature appeared after heating.

A comparison of data from two basalts, with respectively normal and inverse directions of natural thermoremanence, gave no indication that a property of the material caused the inverse polarization in one of the rocks. The results supported the hypothesis that such magnetizations owe their direction to past reversals of the geomagnetic field. 


\section{Acknowledgments}

The author wishes to express his gratitude to Prof. J. M. Bruckshaw for his help and encouragement throughout the work. In addition, the author wishes to thank Dr. G. D. Nicholls of the Geology Department, University of Manchester, for being kind enough to analyze some of the specimens. For their kind assistance whilst at the Geophysics Department, Imperial College, special thanks are due to Dr. J. Singh, Dr. M. Fahim and Dr. S. K. Dutt. The author is also grateful to the Anglo-Iranian Oil Co., and the Anglo-Saxon Oil Co., for providing the financial basis for this research.

\section{References}

[1] Bruckshaw, J.M. and Robertson, E.I. Roy. Astron. Soc. Geophys. Suppl. 5, 308 (1949).

[2] Bruckshaw, J.M. and Vincenz, S.A. Roy. Astron. Soc. Geophys. Suppl. 6, 579 (1954).

[3] Vincenz, S.A. Roy. Astron. Soc. Geophys. Suppl. 6, 590 (1954).

[4] Néel, L. Ann. de Phys. 3, 137 (1948).

[5] Nagata, T. Nature (London) 169, 704 (1952).

[6] Nagata, T., Akimoto, S., and Uyeda, S. J. Geomag. Geoslec. 4, 22, 102 (1952). 5, 168 (1953).

[7] Bruckshaw, J.M. and Rao, B.S. Proc. Phys. Soc. (London) 63, 931 (1950).

[8] Koenigsberger, J.G. Phys. Zeits. 33, 468 (1932).

[9] Akimoto, S. Private Communication (1954).

[10] Forrer, R. Jour. Phys. Rad. 2, 312 (1931).

[11] Akimoto, S. J. Geomag. Geoelec. 6, 1 (1954).

[12] Akimoto, S. Jap. J. Geophys. 1 (2), 1 (1955).

[13] Roquet, J. Comp. Rend. (Paris) 224, 1418 (1947).

[14] Koenigsberger, J.G. Terr. Mag. 43, 119, 299 (1938).

[15] Nagata, T. Rock Magnetism, p. 88 (Tokyo: Maruzen and Co., Ltd., 1953).

[16] Néel, L. Rev. Mod. Phys. 25, 58 (1953).

[17] Davis, C.W. Physics, 6, 376 (1935).

[18]. Tzu-Chang-Wang. Zeits. f. Geophys. 16, 163 (1940).

[19] Wologdine, M. Comp. Rend. (Paris) 148, 776 (1909).

[20] Bates, L.F. Modern Magnetism, p. 323. (Cambridge University Press, 1951).

[21] Singh, J. An Investigation into the process of magnetization of rocks. Ph. D. Thesis, University of Lonàon, (1954). 